Supporting Information

\title{
Rare-Earth Silylamide-Catalyzed Selective Dimerization of Terminal Alkynes and Subsequent Hydrophosphination in One-Pot
}

\author{
Kimihiro Komeyama,* Tomonori Kawabata, Katsuomi Takehira, and Ken Takaki*
}

Department of Chemistry and Chemical Engineering, Graduate School of Engineering, Hiroshima University, Kagamiyama, Higashi-Hiroshima 739-8527, Japan

kkome@hiroshima-u.ac.jp

\section{$\underline{\text { List of Contents }}$}

Procedure

Materials

S2

H-H COSY spectra of 7a and 8a (Figure S1) 
Procedure. ${ }^{1} \mathrm{H},{ }^{13} \mathrm{C}$, and ${ }^{31} \mathrm{P}$ NMR spectra were recorded at 400,100 , and $160 \mathrm{MHz}$, respectively. IR spectra were taken on an FT-IR spectrophotometer. Mass spectra (EI) were obtained at $70 \mathrm{eV}$ on a GC-MS apparatus. Melting points are uncorrected. All reactions were carried out under argon.

Materials. Toluene was distilled from sodium/benzophenone ketyl immediately prior to use. $\mathrm{Ln}\left[\mathrm{N}\left(\mathrm{SiM}_{3}\right)_{2}\right]_{3}$ were prepared from anhydrous $\mathrm{LnCl}_{3}$ and $\mathrm{NaN}\left(\mathrm{SiMe}_{3}\right)_{2}{ }^{1}$ in THF, according to the literature. ${ }^{2}$ The alkynes $\mathbf{1 b}, \mathbf{1 c}, \mathbf{1 e},{ }^{3} \mathbf{1 d},{ }^{4}$ and $\mathbf{1 \mathbf { f } ^ { 5 }}{ }^{5}$ were prepared by the reported methods. Diphenylphosphine was prepared by reduction of triphenylphosphine with lithium metal in THF. All other materials were commercially available and were used after drying and distillation.

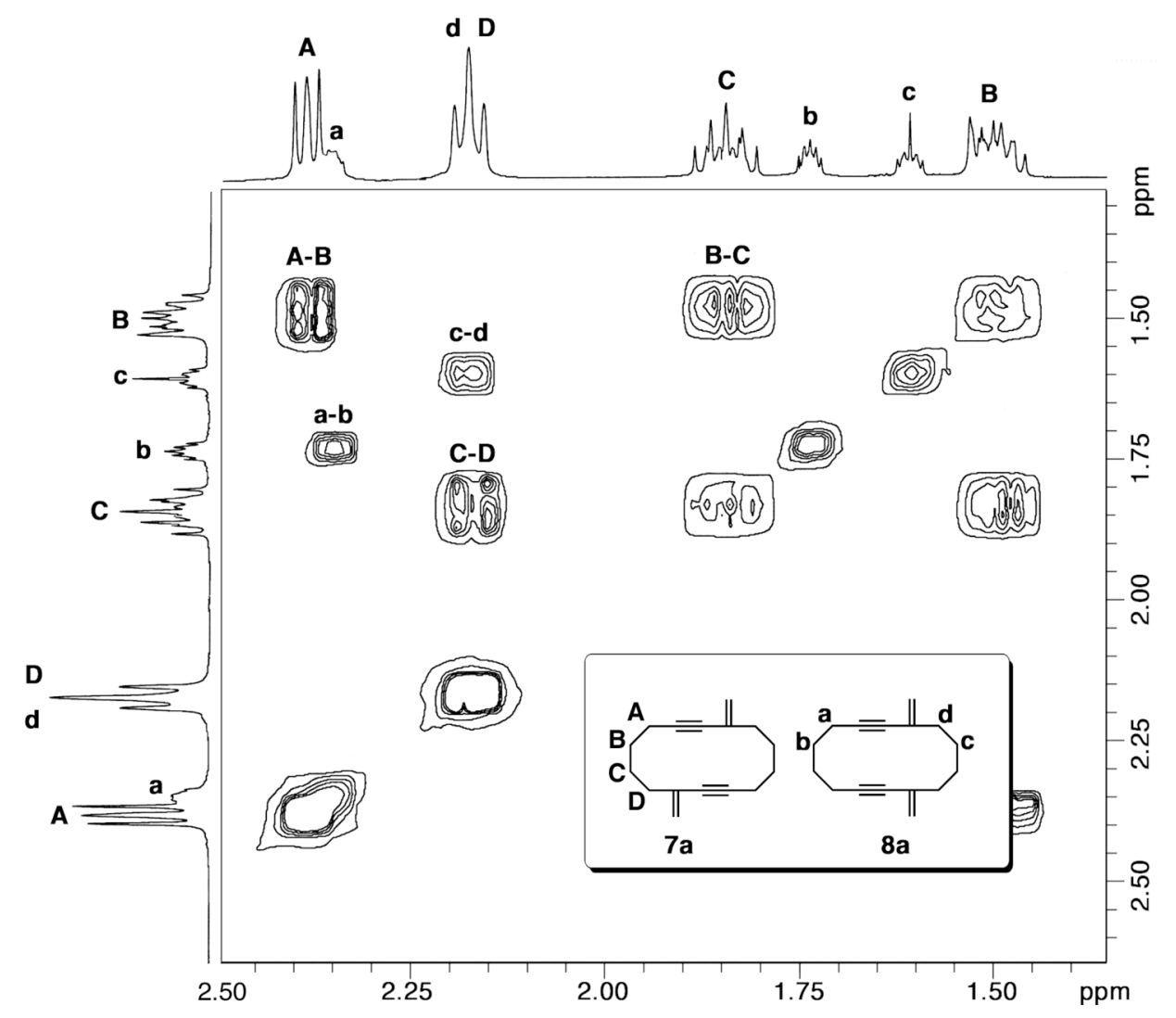

Figure S1. H-H COSY Spectra of 7a and 8a 


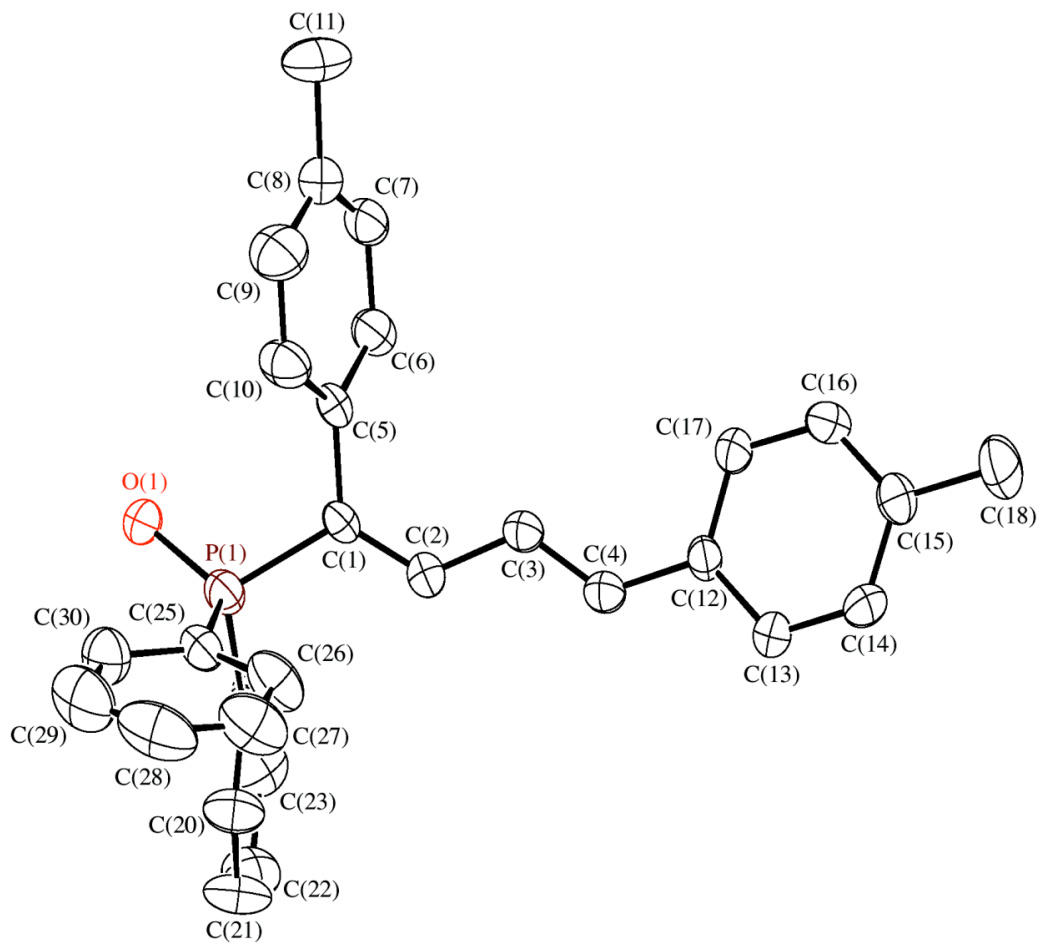

Figure S2. ORTEP drawing of 10c.

\section{References}

(1) Kruger, C. R.; Niederprum, H. Inorg. Synth. 1966, 8. 15-19.

(2) Bradley, D. C.; Ghotta, J. S.; J. Chem. Soc., Dalton Trans. 1973, 1021-1023.

(3) Negishi, E.; Kotora, M.; Xu, C. J. Org. Chem. 1997, 62, 8957-8960.

(4) Jiang, X. K.; Ji, G. Z.; Wang, D. Z. R. J. Fluorine. Chem. 1996, 79, 173-178.

(5) Hommes, H.; Verkruijsse, H. D.; Brandsma, L. J. Chem. Soc., Chem. Commun. 1981, 366-367. 